\title{
Modernizing Political Science: A Model-Based Approach
}

\author{
Kevin A. Clarke and David M. Primo
}

\begin{abstract}
Although the use of models has come to dominate much of the scientific study of politics, the discipline's understanding of the role or function that models play in the scientific enterprise has not kept pace. We argue that models should be assessed for their usefulness for a particular purpose, not solely for the accuracy of their predictions. We provide a typology of the uses to which models may be put, and show how these uses are obscured by the field's emphasis on model testing. Our approach highlights the centrality of models in scientific reasoning, avoids the logical inconsistencies of current practice, and offers political scientists a new way of thinking about the relationship between the natural world and the models with which we are so familiar.
\end{abstract}

T he use of models has come to dominate much of the scientific study of politics. We use models, mathematical or otherwise, to investigate and illuminate causal mechanisms, generate comparative statics, and understand the conditions under which we expect certain outcomes to occur. While our use of models has grown dramatically, our understanding of the role or function that models play in the scientific enterprise has not kept pace.

Throughout the 1970s and 80s, models were treated as tools for conceptual exploration, and little was to be gained by testing either their assumptions or their predictions. Moe, for instance, argued that rational choice models are

Kevin A. Clarke is Assistant Professor, Department of PoliticalScience,University ofRochester(kevin.clarke@rochester.edu) and David M. Primo is Assistant Professor, Department of Political Science, University of Rochester (david.primo@ rochester.edu). Earlier versions of this paper were presented at the 2004 Annual Meeting of the American Political Science Association and at the 2005 Annual Meetings of the Midwest Political Science Association and the Canadian Political Science Association; we thank the participants for their comments. We thank Chris Achen, Jim Alt, Jake Bowers, Henry Brady, Bear Braumoeller, John Duggan, Mark Fey, Rob Franzese, John Freeman, Gary Goertz, Miriam Golden, Jim Granato, Gretchen Helmke, John Jackson, Keith Krehbiel, Skip Lupia, Scott de Marchi, Andrew Martin, Becky Morton, Bob Pahre, Kevin Quinn, Curt Signorino, Randy Stone, and three anonymous reviewers for helpfulcomments and discussion. We also thank Matt Jacobsmeier for research assistance. Support from the National Science Foundation (Clarke: Grant\#SES-0213771, Primo: Grant\#SES0314786) is gratefully acknowledged. devoid of empirical content, and Achen warned that mathematical models "are to be used and not believed." 1 Theoretical modelling sometimes informed data analysis and vice versa, but with few exceptions, the field was divided into theorists and empiricists.

As models in political science became more prevalent, the uses to which we put those models shifted significantly, and today, the emphasis is on using models to generate testable predictions that serve as hypotheses for subsequent data analysis, which in turn is interpreted as a test of the model. The field has created a hierarchy of models where those that are "tested" are valued more highly than those that are not tied to a regression analysis. While much ink has been spilled arguing for this test-the-model approach to the study of political science, little attention has been paid to justifying and rationalizing the method. On the rare occasions that justification has been attempted, the results have been maddeningly vague. Why test predictions from a deductive, and thus truth-preserving, system? What can be learned from such a test? If a prediction is not confirmed, are assumptions already known to be false to blame? These questions are never addressed in a satisfactory way.

Lack of a suitable justification for model testing is not the only reason to revisit the role of models in political science. The emphasis on model testing has led to a distortion of both the modelling process and the art of data analysis. Preferring models that predict well has led the field to devalue the other important contributions that models can make to understanding the political world. The emphasis on using data analysis as a means for testing models turns regressions into hypothesis-testing machines and ignores the role that data analysis can play in producing empirical generalizations that may serve as a spur to further modelling efforts. 
Rethinking our use of models in political science is of critical importance, as a generation of scholars is being trained to think about science in an outdated and inadequate manner. The success of the Empirical Implications of Theoretical Models (EITM) project has highlighted the fact that while political scientists are using models more than ever before, we are still thinking in old ways. The goal of this paper, then, is to modernize political science. Following the work of Suppes, van Fraassen, Suppe, and others, we define a model as an object, not a linguistic entity, and thus neither true nor false. ${ }^{2}$ We specify five uses to which models may be put and argue that model evaluation should proceed in the much the same fashion that mechanical models are evaluated in the physical sciences - good models are useful for particular purposes. This perspective frees political science from the deleterious effects of an over-emphasis on prediction.

What we propose is more than a change in language; we argue for a change in how political scientists construct, perceive, and utilize models. This model-based approach provides new ways to think about the purposes of models in political science, the relationship between models and the empirical world, and the language of scientific inquiry.

\section{What Is a Model?}

Before discussing how models are used, it is necessary to define explicitly what a model is. We do so first through an analogy. Maps are models. ${ }^{3}$ Maps are not reality, nor are they isomorphic to reality. Rather, they are representations of reality. Furthermore, maps are physical objects, not linguistic entities. It therefore does not make sense to ask whether maps are true or false any more than it makes sense to ask if other physical objects - tea kettles, toy airplanes, or gas grills - are true or false. Maps are partial; they represent some features of the world and not others, and they are of limited accuracy. A map is an object representing another object: reality.

The question to ask of a map is not whether it is true or false, but whether the map is similar to the world. The standard objection to this line of reasoning is that two objects may be similar or dissimilar in almost an infinite number of ways. Such objections may be met by specifying in what manner, to what degree, and for what purpose the map is similar to the world. Is the model similar enough to the world to be useful for a specific purpose? A map of a subway line may have little similarity to the geography of a city, and yet be similar enough to the rapid transit system to make it a necessary appendage for all commuters. Thus, as Giere argues, "Maps necessarily reflect the interest of map makers and map users." ${ }^{4}$ That is, they are interest relative.

If theories were linguistic entities, it would make sense to ask whether they are true or false, just as any statement can be true or false. What we argue is that political scien- tists should think of models more like representational objects and less like linguistic entities. ${ }^{5}$ That is, we argue that models in political science should be viewed as maps rather than statements, and we should be asking of our models whether they are similar enough to the world to be used for specific purposes. ${ }^{6}$

To achieve this end, we consider the predicate or semantic (referring to the relation between language and reality, as opposed to syntactic, which refers to the relation between verbal symbols) view of theories most closely associated with the work of Patrick Suppes, Frederick Suppe, Bas van Fraassen, and Ronald Giere. ${ }^{7}$ The benefits of the semantic approach include demonstrating the centrality of models, as well as clarifying the relationship between models and the empirical world. (Models are semantic concepts because we care about the relationship between the model and its referent. $)^{8}$ The semantic view should not be completely unfamiliar to political scientists as it was recently, if briefly, introduced to political science by Henry Brady, who points out that models, under the semantic view, are "akin to tools for probing reality." 9

The most important feature of the semantic approach is that models, not theories, are central to the scientific enterprise. ${ }^{10}$ Giving a precise answer to the question "what is a theory" has even been argued, by a leading proponent of the semantic view, to be unimportant. ${ }^{11}$ For this reason, a theory on the semantic view is typically viewed as a collection of models. ${ }^{12}$

A model is a kind of system whose characteristics are specified by an explicit (and sometimes elaborate) definition. As a model is characterized by a definition, by construction it cannot be falsified. For example, "a Newtonian Particle System is a system that satisfies the three laws of motion and the law of universal gravitation." ${ }^{13}$ That is, the model asserts that a system is a Newtonian Particle System if the system satisfies the three laws of motion and the law of universal gravitation.

The question we should ask of a model is whether or not it is similar in certain respects, and for certain uses, to a system in the real world. ${ }^{14}$ What is important is for a substantive researcher to specify precisely in what ways and for what purposes his or her model is similar to a particular real-world system. "Testing" then becomes a matter not of "confirming a prediction," but assessing whether the degree of similarity between two systems is sufficient for a specific purpose.

Thus, "a model may or may not be suitable . . . but it is neither true nor false, or confirmable, or directly subject to what is usually called induction." 15 "Confirming" a model, on this view, means confirming the empirical claims made about a model. That is, model confirmation consists of evaluating the degree to which a model is similar to a natural system and whether or not it serves the purpose for which it was intended. Such an evaluation goes beyond just using the most recent high-powered data 
Table 1

The Purposes of a Model

\begin{tabular}{|c|c|c|}
\hline Type of Model & Purpose & Example \\
\hline Foundational & $\begin{array}{l}\text { Provide insights into a general } \\
\text { class of problems }\end{array}$ & $\begin{array}{l}\text { Baron \& Ferejohn (1989): } \\
\text { Bargaining in legislative settings }\end{array}$ \\
\hline Structural & $\begin{array}{l}\text { Organize empirical generalizations } \\
\text { or known facts }\end{array}$ & $\begin{array}{l}\text { Achen (1992): } \\
\text { Voting and party ID }\end{array}$ \\
\hline Generative & $\begin{array}{l}\text { Produce non-obvious directions for } \\
\text { further study }\end{array}$ & $\begin{array}{l}\text { Romer \& Rosenthal (1978): } \\
\text { Bargaining over budgets }\end{array}$ \\
\hline Explicative & Explore causal mechanisms & $\begin{array}{l}\text { Knight (2001): } \\
\text { Using counterfactuals to study debates over judicial review }\end{array}$ \\
\hline Predictive & Forecast events or outcomes & $\begin{array}{l}\text { Lewis-Beck \& Rice (1992): } \\
\text { Predicting presidential election outcomes }\end{array}$ \\
\hline
\end{tabular}

analytic technique and allows into the model evaluation process a far wider range of empirical evidence and methodologies. This approach allows substantive researchers the freedom to specify precisely in what ways their models are similar and in what ways their models are dissimilar to the real-world systems that they seek to explain.

\section{The Purposes of a Model}

As models should be assessed for their usefulness for a specific purpose, it is therefore necessary to detail the purposes to which a model can be put and how we can judge whether or not a model is useful. At the most basic level, models can serve in any one (or more) of five different roles: foundational, structural, generative, explicative, and predictive. ${ }^{16}$ Refer to table 1 for an overview and examples.

It is this last function of models, prediction, with which we are most familiar, although actual examples of models whose main purpose is prediction are quite rare. Most of these models can be found in the area of national election forecasting. ${ }^{17}$ That the usefulness of these models should be judged by the success rate of their predictions is made explicit by Campbell in a symposium on election forecasting published in PS: "Each model predicts the share of the national two-party popular vote for the candidates of the major parties ... [and] their evaluation should be based on their success in predicting the vote." 18

In most research, though, a prediction is a hypothesis deduced from a model. This kind of prediction is often seen as the "crucial activity" in science, and models are judged by how well they predict. ${ }^{19}$ However, as Michael Laver notes, prediction is not the "be-all and end-all" of model evaluation. ${ }^{20}$ One of the great strengths of the semantic approach is that it lets us go beyond prediction and judge whether or not a model is useful for a variety of other purposes. The disjunction between usefulness and prediction can be clearly seen if we consider models from a previous age of political science when a lack of predictive accuracy did not doom a model.
The spatial model, first employed in an electoral setting by Downs, is a case in point. ${ }^{21}$ The model predicts that the optimal policy stance in two-party competition is for both parties to locate at the ideal point of the median voter. This result is clearly not borne out empirically; candidates take different policy stances, typically away from the median. Despite this lack of predictive accuracy, the model has been extraordinarily fruitful in providing intuition into candidate competition. In fact, many extensions of the spatial model similarly make predictions that are not accurate. Complete information spatial models of interbranch and legislative bargaining predict that blocking devices such as filibusters and vetoes should not occur, and yet, of course, they do. ${ }^{22}$

As this example demonstrates, the correlation between predictive ability and usefulness is far from perfect. Thus, models can prove useful in other ways. Highly abstract models, for example, may exist to provide foundational results for applied modelers. ${ }^{23}$ Such models may not reflect any real-world situation, and yet may still provide insights into a general class of problems. Consider Arrow's Theorem, which demonstrates that there is no collective choice rule that can translate all possible configurations of individual preferences into a group choice coherently-short of making one individual a dictator. ${ }^{24} \mathrm{~A}$ model may also serve as a foundation for further model-building. Baron and Ferejohn's model of legislative bargaining has been used as the foundation for dozens of applications and extensions. ${ }^{25}$ Finally, a model might connect several other models under one theoretical framework. Banks and Duggan (2000) establish uniqueness results for a class of bargaining models that includes divide-the-dollar games, the spatial model, and models of public goods and exchange economies. Their model also subsumes Black's Median Voter Theorem and Downs's party competition results. ${ }^{26}$

Models that play an organizational or structural role need not be as abstract as those that play a foundational role. Models of this kind provide a "framework wherein 
information may be defined, collected and ordered." 27 One purpose of such a model might be to collect a group of disparate empirical generalizations or known facts under a single framework. The simple prospective model of voting and party identification in a paper by Chris Achen plays precisely this role. ${ }^{28}$ In this paper, Achen demonstrates that his model fits eleven known generalizations and thus "subsumes within a unified framework a broad range of findings in the literature." 29

Models may also serve a generative function. The purpose of these models lies in their "fertility" - the ability to generate interesting and non-obvious statements about the phenomenon of interest. Laver clearly views rational choice models as performing this function and forcefully argues that the purpose of rational choice theory is "the search for interesting and non-trivial tautological arguments." "In "Interesting" and "non-obvious" statements, in this context, refer to counterintuitive results, which are unanticipated prior to the model being solved. Romer and Rosenthal, for example, model a revenue-maximizing agenda setter proposing a budget to voters. ${ }^{31}$ If the voters approve the budget, it is enacted. If the voters fail to approve the budget, a reversion budget automatically goes into effect. The counterintuitive result is that the more austere the reversion budget, the more power the agenda setter has. The reasoning is simple. For austere reversion budgets (those budgets that are lower than either the median voter or the agenda setter would like), there is an inverse relationship between the size of the reversion budget and the budget that is ultimately enacted. That is, the more severe the reversion budget, the greater government spending, and the better off the agenda setter is. The intuition that an agency head should be more fearful of an austere reversion budget than a generous budget is incorrect.

Finally, models may also serve an explicative function, which refers to the fact that we can use models to explore the putative causal mechanisms underlying phenomena of interest. One such method is to ask counterfactual or "what-if" questions. ${ }^{32}$ An excellent example is Knight, who uses two game-theoretic models to analyze the conflict between Jefferson and Marshall over judicial review and then uses the models to ask "what-if" questions: "By varying the relevant conditions in the game, we could assess the relative merits of the historical counterfactuals that underlie the different explanations of this period." 33 In a different example, we could use a model to explore the impact of institutional change on behavior and outcomes. Solving a model of legislative bargaining for different $q$-rules, where $q$ denotes the number of legislators needed for legislation to be enacted, allows an examination of the impact of supermajority requirements on agenda-setter power. ${ }^{34}$ Note that prediction can hardly be the measure of success for models designed to answer "what-if" questions, as such questions concern situations that have not actually occurred. ${ }^{35}$
As models may be used for a myriad of purposes, predictive success cannot be, as it too often is, the only metric by which we assess models. Prediction may, in fact, be orthogonal to a model's goals. Given that models are purpose-relative, proper evaluation must begin with a determination of the model's intent. Once that has been established, we can then ask whether or not the model achieves its stated purpose. Thus, the purpose to which a model is put generates its own metric of success. Models that generate a significant number of interesting statements or counterfactuals are successful, as are models that are routinely used as building blocks for further inquiry. At the same time, it is quite possible to write down models that generate uninteresting, vapid, or narrow results. Models that are useful should survive regardless of their ability to predict, and models that are not useful should simply die from neglect, again, regardless of their ability to predict. ${ }^{36}$

\section{The Political Scientific Method}

In order to draw a clear distinction between the understanding of models outlined in the previous section and the state of the discipline in political science, we need to characterize and critique what serves as the scientific method for much of political science. The technical name for this method is hypothetico-deductivism (H-D), and at first glance, it may appear that we are offering a caricature of political science. However, we follow the discussion with evidence from the documentary record that political scientists do write and think in this way.

The H-D approach comprises the following:

- a hypothesis $H$ set up for testing or examination;

- an observation sentence $O$ implied by $H$ along with theoretical background statements, mixed statements, boundary conditions, etc.; and,

- an experiment or examination of the world where we observe either $O$ or $\sim O{ }^{37}$

If we observe $\sim O$, then we have refuted $H$. If we observe $O$, then we have confirmed $H$ or, at the very least, failed to refute $H .{ }^{38}$ Less formally, "Theory implies prediction (basic sentence, or observation sentence); if prediction is false, theory is falsified; if sufficiently many predictions are true, theory is confirmed." 39

The approach, on its face, appears hard to argue with. What could be more straightforward than deriving a prediction from a model and testing it? As we and many others argue, however, the straightforwardness of the H-D approach collapses as soon as one begins to push past its intuitive appeal. ${ }^{40}$ One particular shortcoming, as relevant to political scientists as it is to philosophers, is that the H-D model fails to specify what testing a deductive implication can tell us about the model in question.

What can one learn about a deductive model from testing an implication of that model? Two states of the world 


\section{Table 2 Possible States of the World}

\section{Cases}

(1)

\begin{tabular}{lll}
\hline Assumptions & True & False \\
Predictions & True & True or False \\
Connection between model and truth of prediction & Logical necessity & None \\
Informativeness of data analysis for "truth" of model & Uninformative & Uninformative \\
\hline
\end{tabular}

are depicted in table 2. The assumptions of a model are either true or false. If the assumptions of the model are true, then the predictions of the model must be true because deductive systems are truth-preserving, and testing is therefore unnecessary and redundant. As Doron and Sened write, "Deductive reasoning has one clear advantage over inductive reasoning - it need not be verified in the empirical world. In fact, it need not even reflect real world phenomena. Its falsification comes about as a result of internal inconsistency." 41

If the assumptions of a model are false, then the predictions of the model may be either true or false. It is not true that if the assumptions are false, then the predictions must be false. (Deductive systems are not falsity-preserving.) Thus, even assuming that models can be true or false, whether or not the prediction is borne out in the data analysis does not inform us about the truth of the model. The accuracy of the predictions is not connected in any necessary way to the model and therefore their accuracy cannot reflect on the model.

Of course, political scientists never know the true state of the world, so it could be argued that false predictions do indicate that the assumptions are false. This argument would be quite valid except that political scientists are well aware that almost all assumptions are false. Data analysis therefore cannot inform a researcher as to whether or not a model is "confirmed." We should note that it is no defense to argue that our assumptions are "approximately true" or "true enough." The truth-preserving properties of a deductive model do not hold when the assumptions are approximate. In the context of a deductive model, "approximately true" equals false.

Testing a prediction or implication deductively derived from a model cannot help us to learn about the model itself. A true prediction cannot tell us that the model is correct, and a false prediction cannot tell us something that we already know. ${ }^{42}$ Testing predictions, however, is not the only way that models may be tested. Morton argues that models can also be evaluated by testing their assumptions. ${ }^{43}$ Given the deductive nature of formal models, this procedure seems intuitively more reasonable than testing implications. Unfortunately, the problem with testing assumptions is very similar to the problem of "discovering" false premises. Generally, we already know that our assumptions are false. Testing assumptions can only confirm our beliefs.

Are political scientists really doing H-D, or have we set up a straw man? Before turning to the evidence, we reiterate that the models to which we refer need not be formal mathematical models. It is quite common for political scientists to derive predictions for testing from informal or verbal models or theories. Examples include Zaller's study of public opinion, Huth and Allee's study of territorial conflict, or Norris's comparative study of electoral rules. ${ }^{44}$ Thus, while our use of the term "model" may appear to restrict our arguments to the small group of political scientists who use formal models, we are in fact addressing a substantial portion of the discipline.

Hypothetico-deductivism is so ingrained in the thinking of most political scientists that it often goes unrecognized. We demonstrate the dependence of our field on $\mathrm{H}-\mathrm{D}$ in two ways. First, we cite the writings of some of the most well-respected scholars in political science, whose work often serves as models for others. Second, we report the results of a survey of recent articles in the top three political science journals. The evidence shows that H-D is the prevailing method of model testing in political science.

Walt and Bawn, for example, argue that the success or failure of a theory hinges on its "empirical validity" established by testing the predictions derived from a model. ${ }^{45}$ Fiorina views the potential for falsifiability as the sine qua non of a model's scientific status, ${ }^{46}$ and Bueno de Mesquita and Lalman write that "the science of modelling depends on the ability to extract testable, falsifiable relationships among variables that follow in a logically coherent fashion, so that the connection between the model's structure and its empirical implications is clear and consistent." ${ }^{47}$ The H-D perspective became so ingrained in the thinking of political scientists that it was institutionalized for a time at the American Journal of Political Science. From 1995 to 1998, all abstracts in the journal had the same four components: theory, hypotheses, methods, and results.

Further examples of the influence of hypotheticodeductivism are easily found throughout the discipline. 
Keith Krehbiel, in a study of legislative committee organization, writes, "to reap the benefits of a joint theoreticalempirical approach, the remainder of this study seeks to conform with orthodox tenets of positive social science. Postulates are empirically motivated. Theoretical assumptions are explicit and precise. Theoretical results follow logically from the assumptions. Empirical predictions are extracted from theoretical results. And empirical predictions are refutable." 48

John Zaller adopts a similarly axiomatic approach to developing testable propositions about public opinion: "The method of this book, then, is to develop deductive implications of the four basic axioms for a given, highly specific set of conditions; review evidence indicating whether or not these implications are empirically correct; and present new evidence as necessary and possible to resolve outstanding empirical questions." ${ }^{49}$

Cameron, Segal, and Songer derive comparative statics from their model and "test them with a random sample of search-and-seizure cases appealed to the Burger Court between 1972 and 1986." Their empirical findings "support the theory." ${ }^{50}$ Clark and Hallerberg study how capital mobility shapes fiscal and monetary policy; they construct a model, "derive predictions about central bank and government behavior under different sets of (ideal typical) structural conditions," "test" the model, and find that the "results largely confirm the theoretical model." 51

Pippa Norris writes that rational-choice institutionalism "makes certain simple assumptions about the selfinterested aims of rational actors and then seeks to outline and test the predictions that flow logically from these premises." ${ }^{52}$ Barbara Geddes, while noting that models may be more or less useful, writes, "If those tests also conform to [deductive] expectations generated by the argument, our confidence that the argument is true will increase." 53

Even a scholar who often writes about methodological issues, such as Chris Achen, uses the language of hypothetico-deductivism liberally. Throughout a recent article on political socialization, Achen writes of deductive propositions being "validated" or assessed. ${ }^{54}$ The fact that the language of hypothetico-deductivism is no longer adequate is evinced by Achen writing of a "stylized model." This language seems more in keeping with the modelbased approach to science that we introduced earlier. (We revisit Achen's article shortly and discuss its deviations from H-D in greater depth.)

Some might object that while political scientists often write in terms of hypothetico-deductivism, they often think about models in more complex terms. This objection raises two problems. First, the only evidence we have regarding what political scientists think is what they write. Second, the objection assumes that how one writes has no influence on how one thinks. While this assumption is almost certainly false, writing in terms of the HD model can have baleful effects on research even if schol- ars think in more sophisticated ways. For instance, writing an article in the H-D format can skew both the kinds of models we construct and the kinds of data analysis we perform. The reason lies in the fact that the H-D perspective views prediction as the crucial activity in science. ${ }^{55}$ Models without directly testable comparative statics therefore are often discounted by many political scientists regardless of the usefulness of the model or the range of other kinds of evidence that may accord with it. ${ }^{56}$ At the same time, the H-D perspective turns data analysis away from constructing statistically accurate descriptions of the data and toward hypothesis testing in service of model evaluation.

Others might claim that quoting leading scholars in the field is anecdotal. To address this claim, we conducted a survey of the three leading generalist journals in political science: American Political Science Review, American Journal of Political Science, and Journal of Politics. Of the 738 articles in these journals between 2001 and 2005, we randomly sampled 10 percent, or 74 articles. Using very conservative coding rules, we identified nearly half of the articles $(46 \%)$ as using or promoting H-D. ${ }^{57}$ Far from being rare, $\mathrm{H}-\mathrm{D}$ is practiced in all subfields, with the exception of political philosophy, and as the above quotes suggest, it is often seen as the gold standard of political science research.

A modern take on the H-D approach to scientific inference in political science is the EITM project. ${ }^{58}$ If we look closely at the writings of the major proponents of the EITM project, a pattern emerges that looks remarkably like hypothetico-deductivism. Using a "steps analogy," Morton, with some simplification on our part, argues for determining predictions (step 2) and evaluating those predictions with an empirical model (step 4)..$^{59}$ Aldrich and Alt, in an introduction to a special issue of Political Analysis, suggest that the challenge of EITM is "to improve our theoretical work so that it yields more testable hypotheses and to improve our methodological work so that testing is made more effective and informative about theories." ${ }^{60}$ Granato and Scioli provide a brief account of a unified EITM world comprising: 1) theory, 2) a model identifying causal linkages, 3) deductions and hypotheses, 4) measurement and research design, and 5) data collection and analysis. ${ }^{61}$ Boiled down to its essence, Granato and Scioli's argument comprises a theory, a deductive model with accompanying implications, and a test. The results of the test are then used to modify the assumptions of the model. That is, the test allows us to learn about the structure of the model.

If there is any remaining doubt that the authors cited above are writing from an H-D perspective, note that the proponents of the hypothetico-deductive method similarly exhort us "to formulate one's hypotheses clearly, to draw testable implications from them by deductively valid reasoning, and to put these implications to experimental test without fear or favor." Kyburg goes on to claim that 
these exhortations are particularly prevalent "in courses in methodology associated with the social and behavioral sciences." 62

\section{An Example}

A detailed example is the clearest way of illustrating the differences between the semantic approach and the current state of the discipline in political science. Presenting such an example is complicated significantly by the fact that despite a recent mention by Brady, and despite having made inroads into biology, psychology, economics, as well the health sciences and physics, the semantic view has yet to inform any discussions of political science. ${ }^{63}$ Pointing to success stories in political science is therefore made somewhat difficult. While we believe that a few of the leading political scientists often think in terms more compatible with the semantic view, they nevertheless often write in terms of the hypothetico-deductive method. Our solution to this dilemma is to examine an existing piece of high-quality political science research that has clearly abandoned the constraints of hypothetico-deductivism, but has yet to abandon the language of hypothetico-deductivism.

Achen recently proposed a rational choice model of political socialization that seeks to understand why children may try on their parents' party identification while at the same time gleefully rejecting their parents' advice on music and style. ${ }^{64}$ The model itself is quite simple. Voters are said to identify with a party when they expect future benefits from that party to exceed future benefits from alternative parties. Voters, uncertain about these future benefits, continually update in light of recent events consistent with Bayes' rule. Non-instrumental considerations, such as emotional attachments to a party, are left out of the model and thus reinforce the stylized nature of the model.

The puzzle is how a new voter, with no experience of her own to guide her, can rationally choose a party. (Bayesian updating takes place in the normal fashion after this initial choice.) The party benefits accruing to a voter, according to the model, depend on the voter's position in society, and the societal positions of parents and children are correlated. Thus, a new voter can draw upon the experience of her parents and estimate her future benefits. She can therefore choose a party rationally based on this estimate and update as she gains experience.

The interesting thing about Achen's paper, for the purposes of this article, is that with the exception of some language, there is no pretense of strictly following the dictates of hypothetico-deductivism. Achen's paper is an archetypal example of the semantic approach to modelbased reasoning, though he almost certainly never intended it as such. As we demonstrate, the choices Achen makes in this paper are perfectly reasonable from a semantic perspective and quite puzzling from an $\mathrm{H}-\mathrm{D}$ perspective. ${ }^{65}$
The key insight of the semantic approach is that models are objects and thus are neither true nor false. Therefore, those scholars discussed earlier who are asking whether or not their models are "confirmed" by the tests that they run are asking the wrong question. The question they should be asking is whether or not their model is similar to the world in a specific way for a specific purpose. It is this question that drives Achen's piece.

At no point in his article does Achen make the claim that his Bayesian model is "confirmed" in the normal sense. Indeed, he specifically notes that "detailed empirical veridicality" is not the goal of the model, and he readily admits that his assumptions are "somewhat inaccurate." Rather, the goal of the model is to account for what we already know about "parental transmission of party identification to children" for the specific purpose of understanding why children behave differently in the political arena than in the social arena.

The first step is to write down a model that is similar to the world in a particular way. For Achen, this means writing down a "stylized model" that generates qualitative predictions "matching the main empirical generalizations." One purpose of Achen's model is therefore clearly structural. He is concerned with accounting for well-known features of political socialization, including the correlation between the partisanship of parents and their children, the relatively larger number of Independents among young voters, and the decay in partisan alignments over time. There is no pretense here that the model just happens to predict these findings; the model was designed to predict these findings. The fact that the resultant model does predict these findings is in no sense a test of the model. Rather, it is an indication that the model is similar to the real world in a particular way for a particular purpose (understanding the actions of new voters). Achen's claim that his model is more useful than the social psychological model for understanding intergenerational transmission of party identification (PID) is in this vein.

Achen is quite content to state in what ways his model is not similar to the real world. For instance, the model ignores the empirical claim that realignment is continuous (secular realignment) and not intermittent. Indeed, Achen notes that "greater realism" would be necessary for data analysis. Empirical verification of the model is not at issue, however. What is at issue is how well the model captures particular features of the real world.

If a model were simply to capture, in a coherent way, known facts about the world, it would make a contribution. One of the advantages of model-based reasoning, however, is the ability to use the model to further explore reality. Achen's model leads to Proposition 5, which states, "All else equal, the greater the changes in party policy across generations, the more centrist the initial PIDs of young voters will be." Achen notes that this proposition has never been investigated. Unlike the proponents of 
"epistemic difference," Achen makes no claims that empirical investigation of this novel proposition will "confirm" his model. Rather, the point is that the model, which is based on empirical findings, has led to new avenues of empirical investigation and is thus generative as well as structural. This kind of give-and-take between theoretical models and empirical findings is consistent with the semantic approach, but has no place under the rules of H-D, where deductive hypotheses are put to empirical test "without fear or favor." 66

To make the point more forcefully, Achen's paper simply does not fit into the "deductive theory, prediction, test" approach to scientific research. Yet, it is unlikely that anyone would argue with either the paper's scientific status or the paper's contribution to the literature. The semantic approach requires the researcher to state the purposes of a model and its similarity and dissimilarity to the world. For Achen, the purpose of the model is to elucidate the intergenerational transmission of party identification. The model is similar to the world in that it explains three known empirical generalizations: the correlation between parents' and children's partisanship, the greater partisan independence of the young, and the decay of partisan alignments over time. The model is dissimilar to the world in that it is unconcerned with secular realignment and ignores the non-instrumental preferences that voters might possess. The model is successful in that it achieves its specific explanatory purpose and directs us to explore the effect of changes in party policy across generations on the centrality of the initial party identification of young voters.

\section{Integrating Models and Data}

The Achen example provides some insight as to how political scientists should approach their research once they have abandoned the practices of hypothetico-deductivism. In what follows, we distill these insights into a set of four "rules" for social scientific research. These rules are meant to be neither exhaustive nor overly strict, but instead are designed to serve as guidelines for integrating models and data.

1. Be clear about the purpose(s) your model is intended to serve. Any political situation may be modelled in an almost infinite number of ways and for a variety of purposes. Thus a researcher should strive to address the question, "why this model and not another?" Answers might reference any of the purposes of a model listed in table 1. One model might be chosen over another because it predicts particularly well. In another case, a model that lays bare a heretofore unrecognized causal mechanism might be chosen despite its lack of predictive success. A third model may be used because of its great fecundity in generating new avenues for research. In this way, the suc- cess of the modelling enterprise can be judged on its own merits and not on the artificial merits of H-D.

2. Abandon the goal of "model testing" as currently practiced. "Model testing" implies using statistical analysis to determine the truth or falsity (or any of the synonyms that political scientists use, such as "supported," "confirmed," "verified," or "validated") of a model, but as discussed earlier, the truth or falsity of a model is not the question. Rather, the point is demonstrating that the model is useful in a particular way. For the maker of a subway map, this work would entail demonstrating that the average commuter could successfully use the map to get from point $A$ to point $B$. For the maker of a structural model, the work would entail showing that a model really does organize the data into a particular framework for understanding.

Whether or not this kind of demonstration requires data analysis depends. For the Achen model discussed in the previous section, data analysis was not required to make a compelling case for the usefulness of his model. One reason that Achen can get away without data analysis in his structural model is that the field of political socialization is peppered with a number of strong empirical generalizations. In a research area with fewer such generalizations, data analysis would be required to make a compelling case.

3. Include a data analysis only when the purpose(s) of your model is served by it. Not all models require an accompanying data analysis. That this point is widely misunderstood was dramatized by the recent reviewerinspired decision (and subsequent retraction) by the editors of the American Journal of Political Science to publish formal theory only when accompanied by data analysis. Of the five different types of models listed in table 1 , only predictive models need be accompanied by some form of data analysis. The reason is, of course, that prediction is the metric by which these kinds of models are judged.

The above does not mean that outside the realm of predictive models data analysis is useless; it means only that data analysis is not a necessity. Krugman writes that a model is good "if it succeeds in explaining or rationalizing some of what you see in the world in a way that you might not have expected." ${ }^{\prime 7}$ However, you often need data analysis to understand what it is that you "see in the world." A researcher should be clear about how the data analysis supports the purpose of the model, and if it does not support the purpose of the model, leave it out.

4. Treat data analysis as more than an endpoint. On those occasions where models and data are integrated, too often the model is carefully developed over the first nine-tenths of the paper while an inconsequential data analysis is tacked on as the final 
one-tenth of the paper, no doubt to appease reviewers. Seeing data analysis simply as an endpoint is an unfortunate consequence of a focus on model testing. In place of an openness to new empirical findings that a model might incorporate and explain is a search for the "three stars" that indicate that the central prediction of the model is "confirmed" or "supported." This mode of research can hardly be referred to as the integration of models and data.

True integration of models and data is not easy. Showing that a model is similar to the world in a particular way for a particular purpose often has description, as opposed to inference, as its goal, and to some political scientists, description is a dirty word evoking atheoretical accounts devoid of conceptual bite. When guided by theory, however, description becomes a powerful tool both for assessing the usefulness of a model and for opening new avenues for theoretical exploration.

Adoption of a model-theoretic approach to political science means more than simply changing the language of research. It means changing the ways in which we think about and practice political science. ${ }^{68}$ With this change comes several advantages. Adoption of our approach would serve to clarify the issues regarding whether or not assumptions should be "realistic." Researchers would be free to state in exactly what ways and for what purposes the assumptions in their models are similar to systems in the natural world. Assumptions might be "real" or not depending on the circumstances. In a similar vein, our approach allows a wider range of evidence, and the burden is on the researcher to show, through whatever means appropriate, that the model in question is similar to the world in a particular way and for a particular purpose. Finally, our approach would serve as a firmer foundation for graduate training than the often incoherent ways in which we currently talk about doing political science. ${ }^{69}$ Only by jettisoning the language and practices of hypothetico-deductivism and adopting a model-theoretic approach to scientific inference can we hope to deal seriously with these problems.

\section{Conclusion}

Political science is a model-based enterprise, but the discipline's understanding of the role and function of models remains rooted in the past. Under the current view, researchers more-or-less treat models as if they are truthful representations of reality and then test them by deriving predictions and using the accuracy of those predictions to judge whether the models are correct. Good models predict well, and bad models predict poorly.

This process, however, rests on two misapprehensions about the nature of models. The first is that models are either true or false, and the second is that we can learn whether or not our models are true or false. We argue instead that models are objects and thus neither true or false. We argue that models should be assessed for their usefulness for a particular purpose, and not solely for the accuracy of their deductive predictions. Models may be foundational, structural, generative, explicative, and/or predictive, and must be judged on the appropriate metric. We argue that viewing models in this way allows a wider range of evidence to be considered and frees empirical investigation from slavish devotion to statistical significance.

The implications of seeing models in this way are far reaching. Pure formal theory can be recognized as being as deeply substantive as any applied formal theory generating testable predictions. Constructing a model to match known facts can be recognized as a useful scientific activity, and a model that generates new directions for empiricists to follow is to be hailed. Our model-based approach highlights the centrality of models in scientific reasoning, avoids the pitfalls of hypothetico-deductivism, and offers political scientists a new way of thinking about the relationship between the natural world and the models with which we are so familiar. Furthermore, our approach brings true integration of models and data to the EITM project, which is currently training the next generation of scholars. Where an emphasis on H-D model testing narrows the range of acceptable research, our approach expands the ways in which models and data may be integrated and frees political science from the methodological straitjacket imposed by current practice.

The leading political scientists have always appreciated the importance of understanding, and when necessary, reimagining, the foundations upon which our work is built. We see this paper as being squarely within this tradition, and we hope to be engaged constructively by others willing to reexamine the underpinnings of our discipline.

\section{Notes}

1 Moe 1979 and Achen 1982, 15.

2 Suppes 1967, van Fraassen 1980, and Suppe 1989.

3 Giere 1999.

4 Ibid., 43.

5 This is not to say that models in political science have a corporeal existence as maps do; you cannot hold a model in your hand. Rather, a model is a kind of system that has some degree of similarity with a natural, or real-world system.

6 Morton 1993 refers to this characteristic of models as "purpose-relativity."

7 Suppes 1967; Suppe 1977, 1989; van Fraassen 1980; Giere 1990. While the semantic and predicate views are theoretically distinct, the two terms are often used interchangeably in practice with little harm. We use the term "semantic."

8 Salmon 1988. 
9 Brady 2004, 296. Interestingly, one of the earliest experimenters with a semantic or model-theoretic approach to theories was none other than John von Neumann of game theory fame; Suppe 1977.

10 The precise formulations we use are drawn mostly, but not entirely, from Giere 1984, which is a textbook, and its presentation is consequently somewhat simplified. The encapsulation is elegant enough, however, to be liberally cited in van Fraassen 1989, Grunbaum and Salmon 1988, and Hausman 1992.

11 Suppes 1967, 63.

12 Salmon 1988 (6) writes that a theory is "a set of models"; Costa and French 1990 (249) write that a scientific theory "can be considered in terms of a description of its set of models"; Downes 1992 (143) writes that scientific theories "consist of families of (mathematical) models"; and Giere 1984 (83) writes that a scientific theory is the "conjunction" of claims regarding models and natural systems.

13 Giere 1984, 81.

14 While we have been writing primarily in terms of formal mathematical models, there is nothing in the semantic approach that restricts its application to such models. This misconception, however, appears to be widespread among opponents of the semantic view; Lloyd 1988. It may well be easier to understand the semantic view when considering mathematical models, but we need not be concerned that adoption of the semantic view will, in some way, threaten a "unified logic" of scientific inference in political science. Scholars who make use of "informal models" (for lack of a better term) may also benefit by thinking in terms of similarity between their models and real-world systems.

15 Hutten 1954, 296.

16 We are open to other possible uses of models. For instance, many of the early social choice models may be seen as normative. We thank Loren King and James Johnson for this point.

17 For example, see the models used by Lewis-Beck and Rice 1992 and described by Campbell and Garand 1999.

18 Campbell 2004, 733.

19 Brady 2004.

20 Laver 1997, 6.

21 Downs 1957.

22 Krehbiel 1998.

23 Gibbard and Varian 1978 (665) describe such models as "ideal models" that are the "description of some ideal case which is interesting either in its own right or by comparison to reality."

24 Arrow 1963.

25 Baron and Ferejohn 1989.

26 Banks and Duggan 2000.

27 Haggett and Chorley 1967, 24.
28 Achen 1992.

29 Ibid., 206. See our extended example drawn from Achen's more recent work.

30 "Tautological" in Laver's sense means "determined by the assumptions and [a] system of logic"; Laver 1997, 6.

31 Romer and Rosenthal 1978.

32 "What-if" questions are often rather loosely referred to in political science as "counterfactuals." For several applications from political science, see Tetlock and Belkin 1996.

33 Knight 2001, 10.

34 For majority rule in an $n$-member, odd-sized legislature, $q=(n+1) / 2$; for unanimity, $q=n$.

35 Laver 1997.

36 The obvious exception here are models for which prediction is the main goal. Such models comprise a small proportion of the political science literature.

37 Kyburg 1988, 65.

38 An equivalent formulation is given by Glymour 1980 b, 322: "A sentence $h$ is confirmed by a sentence $e$ with respect to a theory $T$ if $e$ is true and $h \& T$ is consistent and $h \& T$ entails $e$ but $T$ does not entail $e . "$

39 Putnam 1991, 123.

40 Attempts to justify the supposedly intuitive H-D procedure had, by 1980 , become so complex that one leading philosopher entitled an article "Hypothetico-Deductivism Is Hopeless" (Glymour 1980a), and another was left to argue rather impotently about H-D's ineffable rightness (Grimes 1990). Yet another has argued the problem lies with first-order logic, and that a solution to the problem requires the abandonment of this branch of logic (Waters 1987).

The shortcomings of the H-D approach include, in no particular order, the Quine-Duhem problem, underdetermination, non-deductive predictions, the tacking problem, the problem of quantitative generalization, the paradox of the ravens, and the grue paradox. The Quine-Duhem problem concerns locating the blame in cases of disconfirmation; H-D does not help us understand whether the theory of interest is false, or an auxiliary theory is false. Underdetermination refers to the logical truth that for any finite collection of evidence, there are infinitely many inconsistent hypotheses which entail that evidence. Nondeductive prediction refers to the fact that most hypotheses in science are statistical and thus not deductive. The tacking problem notes if some evidence confirms a hypothesis, then that evidence also confirms the conjunction of the original hypothesis and any other hypothesis whether it is relevant or not. Hempel's paradox of the ravens demonstrates that nonblack, non-ravens confirm "all ravens are black" 
to the same degree as black ravens. The grue paradox refers to the fact that all observed green emeralds confirm the statement "all emeralds are grue," where grue is defined as observed before $2010 \mathrm{AD}$ and green and observed after $2010 \mathrm{AD}$ and blue. Most of these problems are rather technical in nature and need not concern us here.

41 Doron and Sened 2001, 146.

42 Some argue that predicting "novel facts" lends additional confirmation. The proponents of "epistemic difference," however, have yet to overcome serious objections. See White 2003.

43 Morton 1999, 161.

44 Zaller 1992, Huth and Allee 2002, Norris 2004.

45 Walt 1999, Bawn 1999.

46 Fiorina 1994.

47 Bueno de Mesquita and Lalman 1992, 22.

48 Krehbiel 1991, 15.

49 Zaller 1992, 51.

50 Cameron, Segal, and Songer 2000, 101, 107, 113.

51 Clark and Hallerberg 2000, 323, 324, 326.

52 Norris 2004, 252.

53 Geddes 2003, 86.

54 Achen 2002.

55 Brady 2004.

56 A recent debate over editorial decisions at the American Journal of Political Science demonstrates this point. See our discussion on integrating models and data.

57 To be coded as practicing H-D, authors had to either (1) derive, formally or not, testable hypotheses from a model or theory and then make claims about the state of the model or theory based on the outcomes of those tests, or (2) make a statement that model testing should be accomplished by testing hypotheses derived from the model. Political philosophy articles were excluded from the sample. An independent research assistant classified 65 percent of the sample as H-D, and nearly 40 percent of the sample was classified independently as H-D by both the authors and the research assistant.

58 As the essays from the National Science Foundation workshop on EITM make clear, there are numerous and often conflicting definitions of EITM. For some, EITM simply means using empirical generalizations to "discipline" formal theory and vice versa. For others, EITM begins with a puzzle and culminates in the "testing" of a model; National Science Foundation 2002, 19, 25.

59 Morton 1999, 280.

60 Aldrich and Alt 2003, 309.

61 Granato and Scioli 2004, 315.

62 Kyburg 1988, 61. How political scientists came to use the H-D method is explained easily when we reflect on the considerable confusion that exists in political science between theories and models. A theory, according to logical positivism (the philosophical basis for H-D), is a logical calculus along with a set of correspondence rules. The logical calculus is assessed by deriving an implication and testing it against data. It just so happens that the mathematical models used by social scientists are also in the form of a logical calculus. Over time, models assumed the place that theories had held in the logical positivist programme. This usurpation had a significant negative consequence-political scientists assumed that their models should be tested in the same way that the logical positivists claimed theories should be tested.

Those who require direct evidence of the connection between the logical positivist programme and the early rational choice modelers in political science need look no further than the writings of William Riker, a pioneer in the use of rational choice theory in the study of politics. Riker $(1977,13)$, citing the leading logical positivists (Nagel and Hempel, among others), argues for an explicitly "positivistic" or axiomatic view of science. To explain an event, according to Riker $(1990,167)$, is to "subsume it under a covering law that, in turn, is encased in a [deductive] theory." The idea of a covering law comes from Hempel and Oppenheim's (1948) "deductive-nomological" model of explanation, which was the first complete version of hypothetico-deductivism; Brady 2004, 296.

63 Brady 2004; in biology Beatty 1980, Thompson 1983, 1986, 1988, and Lloyd 1988; in psychology Hardcastle 1994; in economics Hausman 1992; in health sciences and physics Suppe 2000.

64 Achen 2002.

65 Achen even refers to "Bayesian voter theory," which is simply a collection of Bayesian models investigating party identification, the effects of political campaigns, and vote choice.

66 Kyburg 1988, 61.

67 Krugman 1994, 49.

68 Language and practice are, of course, endogenous. How we speak and write about research informs the practice of political science.

69 See Morton 1999 for the current state of the discipline.

\section{References}

Achen, Christopher H. 1982. Interpreting and Using Regression. Beverly Hills: Sage.

_ 1992. Social psychology, demographic variables, and linear regression: Breaking the iron triangle in voting research. Political Behavior 14 (3): 195-211. - 2002. Parental socialization and rational party identification. Political Behavior 24 (2): 151-70. 
Aldrich, John, and James Alt. 2003. Introduction to the special issue. Political Analysis 11 (4): 309-15.

Arrow, Kenneth J. 1963. Social Choice and Individual Values. 2nd ed. New York: Wiley.

Banks, Jeffrey S., and John Duggan. 2000. A bargaining model of collective choice. American Political Science Review 94 (1): 73-88.

Baron, David P., and John A. Ferejohn. 1989. Bargaining in legislatures. American Political Science Review 83 (4): 1181-206.

Bawn, Kathleen. 1999. Money and majorities in the Federal Republic of Germany: Evidence for a veto players model of government spending. American Journal of Political Science 43 (3): 707-36.

Beatty, John. 1980. Optimal-design models and the strategy of model building in evolutionary biology. Philosophy of Science 47 (4): 532-61.

Brady, Henry E. 2004. Introduction to symposium: Two paths to a science of politics. Perspectives on Politics 2 (2): 295-300.

Bueno de Mesquita, Bruce, and David Lalman. 1992. War and Reason. New Haven: Yale University Press.

Cameron, Charles M., Jeffrey A. Segal, and Donald Songer. 2000. Strategic auditing in a political hierarchy: An informational model of the Supreme Court's certiorari decisions. American Political Science Review 94 (1): 101-16.

Campbell, James E. 2004. Introduction-The 2004 presidential election forecasts. PS: Political Science \& Politics 37 (4): 733-36.

Campbell, James E., and James C. Garand, eds. 1999. Before the Vote: Forecasting American National Elections. Thousand Oaks, CA: Sage.

Clark, William Roberts, and Mark Hallerberg. 2000. Mobile capital, domestic institutions, and electorally induced monetary and fiscal policy. American Political Science Review 94 (2): 323-46.

da Costa, Newton C.A., and Steven French. 1990. The model-theoretic approach in the philosophy of science. Philosophy of Science 57 (2): 248-65.

Doron, Gideon, and Itai Sened. 2001. Political Bargaining: Theory, Practice and Process. London: Sage.

Downes, Stephen M. 1992. The importance of models in theorizing: A deflationary semantic view. PSA 1992: Proceedings of the Biennial Meeting of the Philosophy of Science Association 1: 142-53.

Downs, Anthony. 1957. An Economic Theory of Democracy. New York: Harper and Row.

Fiorina, Morris P. 1994. Response to Born. Legislative Studies Quarterly 19 (1): 117-25.

Geddes, Barbara. 2003. Paradigms and Sand Castles: Theory Building and Research Design in Comparative Politics. Ann Arbor: The University of Michigan Press.

Gibbard, Allan, and Hal R. Varian. 1978. Economic models. Journal of Philosophy 75 (11): 664-77.
Giere, Ronald N. 1984. Understanding Scientific Reasoning. 2nd ed. New York: Holt, Rinehart, and Winston. - 1990. Explaining Science: A Cognitive Approach. Chicago: University of Chicago Press.

- 1999 . Using models to represent reality. In Model-Based Reasoning in Scientific Discovery, ed. L. Magnani, N.J. Nersessian, and P. Thagard. New York: Kluwer Academic/Plenum Publishers.

Glymour, Clark. 1980a. Hypothetico-deductivism is hopeless. Philosophy of Science 47 (2): 322-25.

- 1980b. Theory and Evidence. Princeton: Princeton University Press.

Granato, Jim, and Frank Scioli. 2004. Puzzles, proverbs, and omega matrices: The scientific and social significance of empirical implications of theoretical models (EITM). Perspectives on Politics 2 (2): 313-23.

Grimes, Thomas R. 1990. Truth, content, and the hypothetico-deductive method. Philosophy of Science 57 (9): 514-22.

Grunbaum, Adolf, and Wesley C. Salmon, eds. 1988. The Limitations of Deductivism. Pittsburgh Series in Philosophy and History of Science. Berkeley, CA: University of California Press.

Haggett, Peter, and Richard J. Chorley. 1967. Models, paradigms, and the new geography. In Models in Geography, ed. Richard J. Chorley and Peter Haggett. London: Methuen and Co., LTD.

Hardcastle, Valerie Gray. 1994. Philosophy of psychology meets the semantic view. PSA 1994: Proceedings of the Biennnial Meeting of the Philosophy of Science Association 2: 24-34.

Hausman, Daniel M. 1992. The Inexact and Separate Science of Economics. Cambridge: Cambridge University Press.

Hempel, Carl G., and Peter Oppenheim. 1948. Studies in the logic of explanation. Philosophy of Science 15 (2): 135-75.

Huth, Paul K., and Todd L. Allee. 2002. The Democratic Peace and Territorial Conflict in the Twentieth Century. New York: Cambridge University Press.

Hutten, E.H. 1954. The role of models in physics. British Journal for the Philosophy of Science 4 (16): 284-301.

Knight, Jack. 2001. "Law and Rational Choice." Working paper.

Krehbiel, Keith. 1991. Information and Legislative Organization. Ann Arbor, MI: University of Michigan Press.

- 1998. Pivotal Politics. Chicago: University of Chicago Press.

Krugman, Paul. 1994. The fall and rise of development economics. In Rethinking the Development Experience, ed. Lloyd Rodwin and Donald A. Schon. Washington: Brookings Institution Press.

Kyburg, Henry E. 1988. The justification of deduction in science. In The Limitations of Deductivism, ed. 
Adolf Grunbaum and Wesley C. Salmon. Pittsburgh Series in Philosophy and History of Science. Berkeley, CA: University of California Press.

Laver, Michael. 1997. Private Desires, Political Action. Thousand Oaks, CA: Sage.

Lewis-Beck, Michael S., and Tom W. Rice. 1992. Forecasting Elections. Washington, DC: CQ Press.

Lloyd, Elizabeth A. 1988. The semantic approach and its application to evolutionary theory. PSA 1988: Proceedings of the Biennnial Meeting of the Philosophy of Science Association 2: 278-85.

Moe, Terry M. 1979. On the scientific status of rational models. American Journal of Political Science 23 (1): 215-43.

Morton, Adam. 1993. Mathematical models: Questions of trustworthiness. British Journal for the Philosophy of Science 44 (4): 659-74.

Morton, Rebecca B. 1999. Methods and Models: A Guide to the Empirical Analysis of Formal Models in Political Science. Cambridge: Cambridge University Press.

National Science Foundation. 2002. "EITM: Empirical Implications of Theoretical Models Report." Publication of the Political Science Program.

Norris, Pippa. 2004. Electoral Engineering: Voting Rules and Political Behavior. New York: Cambridge University Press.

Putnam, Hilary. 1991. The "corroboration" of theories. In The Philosophy of Science, ed. Richard Boyd, Philip Gasper, and J.D. Trout. Cambridge, MA: MIT Press.

Riker, William H. 1977. The future of a science of politics. American Behavioral Scientist 21 (1): 11-38.

. 1990. Political science and rational choice. In Perspectives on Positive Political Economy, ed. James E. Alt and Kenneth A. Shepsle. New York: Cambridge University Press.

Romer, Thomas, and Howard Rosenthal. 1978. Political resource allocation, controlled agendas, and the status quo. Public Choice 33 (11): 27-43.

Salmon, Wesley C. 1988. Introduction. In The Limitations of Deductivism, ed. Adolf Grunbaum and Wesley C. Salmon. Pittsburgh Series in Philosophy and His- tory of Science. Berkeley, CA: University of California Press.

Suppe, Frederick. 1977. The Structure of Scientific Theories. 2nd ed. Chicago: University of Illinois Press. 1989. The Semantic Conception of Theories and Scientific Realism. Chicago: University of Illinois Press.

- 2000. Understanding scientific theories: An assessment of developments, 1969-1998. Philosophy of Science 67 (3, Supplement): S102-S115.

Suppes, Patrick. 1967. What is a scientific theory? In Philosophy of Science Today, ed. Sidney Morgenbesser. New York: Basic Books.

Tetlock, Philip E., and Aaron Belkin, eds. 1996. Counterfactual Thought Experiments in World Politics. Princeton, NJ: Princeton University Press.

Thompson, Paul. 1983. The structure of evolutionary theory: A semantic approach. Studies in History and Philosophy of Science 14 (September): 215-29.

. 1986. The interaction of theories and the semantic conception of evolutionary theory. Philosophica 37 (1): 73-86.

1988. Explanation in the semantic conception of theory structure. PSA 1988: Proceedings of the Biennial Meeting of the Philosophy of Science Association 2: 286-96.

van Fraassen, Bas C. 1980. The Scientific Image. New York: Oxford University Press.

- 1989. Laws and Symmetry. Oxford: Clarendon Press.

Walt, Stephen M. 1999. Rigor or rigor mortis? Rational choice and security studies. International Security 23 (1): 5-48.

Waters, Kenneth. 1987. Relevance logic brings hope to hypothetico-deductivism. Philosophy of Science 54 (3): 453-64.

White, Roger. 2003. The epistemic advantage of prediction over accommodation. Mind 112 (448): 653-83.

Zaller, John R. 1992. The Nature and Origins of Mass Opinion. New York: Cambridge University Press. 